\title{
Parameters Estimation in Modelling of Gas-Gap in RBMK Type Reactor Using Bayesian Approach
}

\author{
Inga ŽUTAUTAITĖ-ŠEPUTIENE் ${ }^{1}$, Juozas AUGUTIS ${ }^{1}$, \\ Laimutis TELKSNYS ${ }^{2}$ \\ ${ }^{1}$ Vytautas Magnus University \\ Viliekos 8, LT-44404 Kaunas, Lithuania \\ ${ }^{2}$ Institute of Mathematics and Informatics \\ Akademijos 4, LT-08663 Vilnius, Lithuania \\ e-mail: i.zutautaite@if.vdu.lt,telksnys@ktl.mii.lt
}

Received: July 2009; accepted: April 2010

\begin{abstract}
This study presents developed algorithm for assessment and updating estimates of parameters in the mathematical models of non-stationary processes (for instance, system ageing model, dynamic system models and so on) with respect of prior information and new obtained observations. Proposed algorithm for updating estimates of random parameters is based on modified application of Bayesian approach (BA). Developed algorithm was applied for Ignalina NPP Unit 2 RBMK-1500 reactor's closure of the gas-gap between the pressure tubes and the graphite bore probabilistic analysis.
\end{abstract}

Keywords: Bayesian approach, non-stationary processes, ageing.

\section{Introduction}

Information systems are very important for management, control, optimization of processes in the exploitation of complex systems or object (for instance, nuclear power plants, airports); these systems are used for decisions taking with reference of developed mathematical models, obtained observations, performed calculations. System' reliability or efficiency can change because of system' ageing. System' ageing, which could be understood as a general process in which characteristics of components, systems and structures ("equipment") gradually change with time or use, eventually leads to degradation of materials subjected to service conditions and could cause a reduction in component and systems safety margins. In order to avoid problems during device operation time it is important to evaluate effect of ageing phenomena. Therefore mathematical models that describe ageing phenomena are necessary. Contribution of probabilistic assessment of ageing process is significant to strategic planning of devices control, information systems engineering that maintains different level requirements (Čaplinskas, 2009) by utilizing intelligent systems optimization and statistical learning (Dzemyda and Sakalauskas, 2009). The process of system' ageing can be characterized by increasing failure rate or other characteristics that depends on time (or other factors). 
Sometimes approximate trend of system' dynamics describing characteristic as function of some factors and parameters is priory known. However prior information can lead some uncertainty and parameters of this dependence are assumed as random variables with prior pdfs. These distributions (and also trend function) are updated using available statistical data by modified applying of Bayesian approach for its prior distributions.

Developed algorithm was applied for updating estimates of parameters in graphite bore (in Ignalina nuclear power plant RBMK-1500 type reactor' core) diameter dependence on energy burn-up function. The RBMK reactor is designed to use a graphite moderator in the form of graphite bores which surround pressure tubes containing the nuclear fuel and coolant. The pressure tube is initially positioned in place by a series of graphite rings that are alternately in contact with the inner bore hole of the graphite bores and the outer perimeter of the pressure tubes. The initial design was to provide a nominal 2.5-3 mm gap between the pressure tubes and the rings. Fig. 1 presents the scheme of pressure tube, graphite rings and graphite bore and the position of the gas-gap. The interaction of the fast neutrons leads to dimensional changes in graphite and pressure tube materials.

For example, in graphite moderated reactors, initial accumulation of the fast neutron dose produces a gradual shrinkage of the graphite blocks. For the RBMK reactors this results in a decrease of the bore diameter through which the pressure tube passes. For the pressure tube made of a Zirconium and $2.5 \%$ Niobium alloy, the effect is opposite: due to thermal and irradiation' effects the tube diameter increases.

For example, SAR (1996) and RSR (1997) of the Ignalina NPP concluded that closure of the gas-gap between the pressure tube and graphite bore is one of the most important reactor operation lifetime criteria. Therefore there was performed a research for development of the gas-gap existence criterion. The performance of probability analysis for gas-gap closure in Unit 2 is quite difficult because of the lack of statistical data. In last two years no measurements were taken in Unit 2 (shut down of Unit 1 was in 2004). The main objectives of this task are:

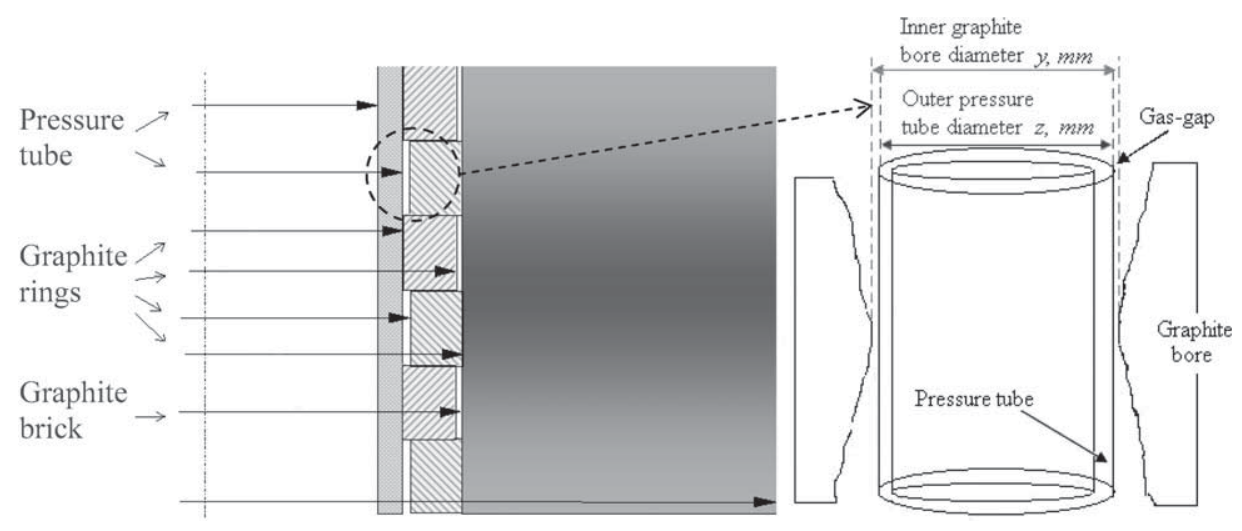

Fig. 1. Scheme of pressure tube-graphite bore gas-gap. 
1. to update parameters' estimates of graphite bore diameters dependence on burn-up function using Bayesian approach incorporating measurements of Unit 2. Perform analogous calculations to obtain updated pressure tube diameter' dependence on burn-up function;

2. to use obtained parameters' density functions for construction of the mathematical model of gas-gap that could be updated when gas-gap measurements in Unit 2 would be made using ultrasonic technology.

Tentatively Ignalina NPP is going to be closed at the end of 2009, in order to cut down expenses of measuring, using of ultrasonic technology is preferred then old one (taking out of technological channels and direct measuring of minimal graphite bore diameters and maximal pressure tube diameters). Ultrasonic technology provides to measure gasgap directly (without taking out technological channels), so there is necessity to change current mathematical model for the gas-gap existence probabilistic analysis.

\section{Bayesian Approach for Non-Stationary Characteristics}

\subsection{Modified Application of Bayesian Approach}

Commonly Bayesian approach is applied to update estimated parameters of stationary process when more statistical information becomes available. But often there is need to deal with problems that are related to non-stationary processes. In such case available statistical data cannot be used to update characteristics of previous period, because it represents the other state of the system. Analyzing non-stationary process required information are:

- distribution of statistical data;

- form of the trend of system' dynamics describing characteristic $\xi($ as function of some factors $F_{1}, \ldots, F_{r}$ and parameters $\theta_{1}, \ldots, \theta_{s}: f\left(\theta_{1}, \ldots, \theta_{s}, F_{1}, \ldots, F_{r}\right)$, for example, it is exponential, polynomial, linear, etc. Expected value of random nonstationary characteristic $\xi$ satisfies requirement

$$
E \xi=f\left(\theta_{1}, \ldots, \theta_{s}, F_{1}, \ldots, F_{r}\right)
$$

Note that parameters of distribution of statistical data/observations are expressed in respect Eq. (2.1) must be satisfied. BA is applied to update random unknown parameters $\theta_{1}, \ldots, \theta_{s}$ of the function defined by Eq. (2.1).

In respect of uncertainty of prior information, maybe noisily measurement and etc., parameters $\theta_{1}, \ldots, \theta_{s}$ of considering model are assumed as random independent variables with a priori known their distributions (otherwise non-informative, for instance, uniform distribution can be used as prior; note that their prior pdfs are $\left.p_{l}\left(x_{l}\right), l=1, \ldots, s\right)$.

Assume that distribution of statistical data $y_{i}, i=1, \ldots, m$, is also known, i.e., likelihood function $-L(\cdot)$ that satisfies Eq. (2.1). Posterior multidimensional density function 
is obtained by application of Bayesian formula for this information

$$
\begin{aligned}
& \varphi\left(x_{1}, \ldots, x_{s} \mid y_{1}, \ldots, y_{i}\right) \\
& \quad=\frac{\prod_{l=1}^{s} p_{l}\left(x_{l}\right) \cdot L\left(y_{1}, \ldots, y_{i} \mid x_{1}, \ldots, x_{s}\right)}{\int_{R_{1}} \ldots \int_{R_{s}} \prod_{i=1}^{s} p_{l}\left(u_{l}\right) \cdot L\left(y_{1}, \ldots, y_{i} \mid u_{1}, \ldots, u_{s}\right) \mathrm{d} u_{1} \ldots \mathrm{d} u_{s}},
\end{aligned}
$$

$i=2, \ldots, m, R_{l}$ - range (set of all possible values) of parameter $\theta_{l}, l=1, \ldots, s$.

So Bayesian estimate (expected value of posterior distribution) of parameter $\theta_{l}$ is

$$
\begin{aligned}
\hat{\theta}_{l i} & =\int_{R_{1}} \ldots \int_{R_{l}} \ldots \int_{R_{s}} x_{l} \cdot \varphi\left(x_{1}, \ldots, x_{l}, \ldots, x_{s} \mid y_{1}, \ldots, y_{i}\right) \mathrm{d} x_{1} \ldots \mathrm{d} x_{l} \ldots \mathrm{d} x_{s}, \\
i & =2, \ldots, n .
\end{aligned}
$$

The power of application BA for updating model is that BA allows us to update estimates of all parameters in the model with a single new obtained observation. On other hand there are some disadvantages of BA application for updating model of nonstationary process. Application of BA couldn't change behavior of the model (for instance, if the model was chosen as linear application of BA can't change it).

Some complications arise in practical computation of integral that appears in denominator of Bayes formula. Some simplifications for this problem are possible (of instance, using conjugated pairs of prior density function and likelihood function $=$ avoidance of numerical calculation of integral gives convenient application of BA).

\subsection{Bayesian Point and Interval Estimates}

The main result of BA application is updated pdf of random parameter(s) that is used to calculate point or interval estimate of considered random parameter.

Depending on likelihood function, some prior distributions can always lead to posterior distribution, which has the same functional form as the prior distribution, for instance, Normal likelihood leads conjugate posterior Normal distribution. This statistical property is related with so-called conjugate pair of prior distribution and likelihood (Bernardo et al., 2003). Using the conjugate pairs the mean and variance as well as other parameters can be easily estimated for posterior distribution. Using conjugate pair of likelihood and prior numerical errorless and convenient algorithms for updating distributions can be developed (Littlewood et al., 2000).

If $p\left(x \mid y_{1}, \ldots, y_{n}\right)$ is posterior pdf of random parameter $\theta$ obtained by Bayesian formula, Bayesian point estimate of random parameter $\theta$ is calculated as expected value of posterior distribution

$$
\begin{aligned}
& \hat{\theta}=E \theta=\int_{R_{\theta}} x \cdot p\left(x \mid y_{1}, \ldots, y_{n}\right) \mathrm{d} x, \\
& R_{\theta}-\text { range (set of all possible values) of parameter } \theta .
\end{aligned}
$$

Main of criterion to evaluate of uncertainty of the Bayesian estimate is analysis of its variance. In generally it is difficult to make research of it because variance is expressed 
as integral. Except some cases of the convergence of Bayesian estimates are presented (when conjugate pairs are used). In case of prior Normal pdf and Normal likelihood, expected value and variance are

$$
\begin{aligned}
& E \mu_{n}=\mu_{n}=\frac{\sigma^{2} \mu_{0}+\sigma_{0}^{2} \sum_{i=1}^{n} y_{i}}{\sigma^{2}+n \sigma_{0}^{2}}, \quad \operatorname{Var} \mu_{n}=\sigma_{n}^{2}=\frac{\sigma^{2} \sigma_{0}^{2}}{\sigma^{2}+n \sigma_{0}^{2}}, \\
& \operatorname{Var} \mu_{n}=\sigma_{n}^{2}=\frac{\sigma^{2} \sigma_{0}^{2}}{\sigma^{2}+n \sigma_{0}^{2}} \underset{n \rightarrow \infty}{\rightarrow} 0,
\end{aligned}
$$

with any statistical data; rate of convergence $-\frac{1}{n}$, here $n-$ amount of statistical data. In presented case the variance of Bayesian estimate is decreasing with convergence rate not lower than $1 / n$.

In systems' reliability analysis estimates of model parameters are not always sufficient; it is necessary to obtain its confidence intervals (with a given confidence level) as well. Sometimes it's necessary to construct modified asymmetric confidence interval. For instance, if the beginning (or the ending) of this interval has higher importance for reliability analysis. The definition of this kind of interval is following.

DEFinition. Asymmetric confidence interval of the unknown true value of $\theta$, for a given significance level $\alpha$, is credible interval $\left[\hat{x}_{1}, \hat{x}_{2}\right]$ that satisfies these equalities

$$
\begin{aligned}
& P\left(x_{1} \leqslant \theta \leqslant x_{2}\right)=1-\alpha, \\
& P\left(\theta<x_{1}\right)=c \alpha, \quad P\left(\theta>x_{2}\right)=(1-c) \alpha, \quad 0<c<1 .
\end{aligned}
$$

For instance, the asymmetric confidence interval of Normal random variable (i.e., $N(\mu, \sigma))$ is $\left[\mu-u_{c \alpha} \cdot \sigma ; \mu+u_{(1-c) \alpha} \cdot \sigma\right]$, here $u$. - quantile of standard Normal distribution.

Developed algorithm was applied for updating estimates of parameters in graphite bore (in Ignalina nuclear power plant RBMK-1500 type reactor' core) diameter dependence on energy burn-up function.

\section{BA Application for Modeling of Graphite Changes in Nuclear Reactor}

\subsection{Statistical Data Analysis}

To monitor the gas-gap closure of the Ignalina NPP, two types of diameters were measured: outer pressure tube $(P T)$ diameter $z(\mathrm{~mm})$ and inner graphite bore $(G B)$ diameter $y(\mathrm{~mm})$ (see Fig. 1). During entire Ignalina NPP operation period there were performed 1682 measurements of pressure tube and 300 graphite bores of Unit 1, 1460 and 42 measurements respectively of Unit 2. Data of graphite bore minimal diameters and pressure tube maximal diameters measurements are presented in Figs. 2-3.

As the RBMK type reactors due to radiation and thermal conditions have property changes in core active zone, the analysis of graphite bore, rings and pressure tube diameter change during operation was performed with finite element computer code ABAQUS 


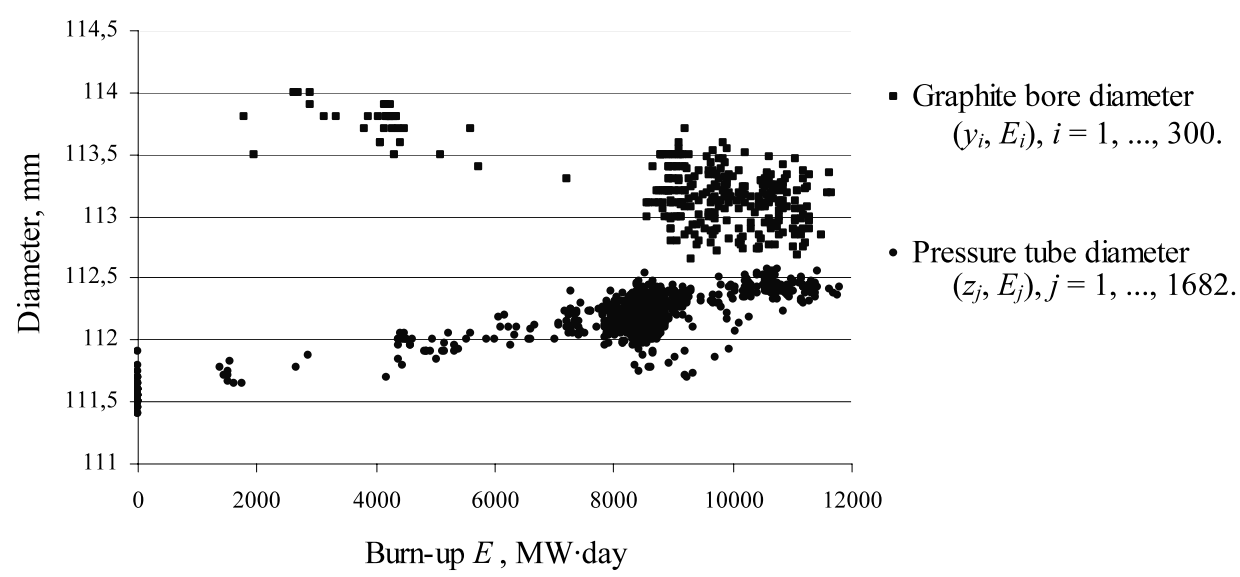

Fig. 2. Minimal graphite bore diameters and maximal pressure tube diameters in Unit 1.

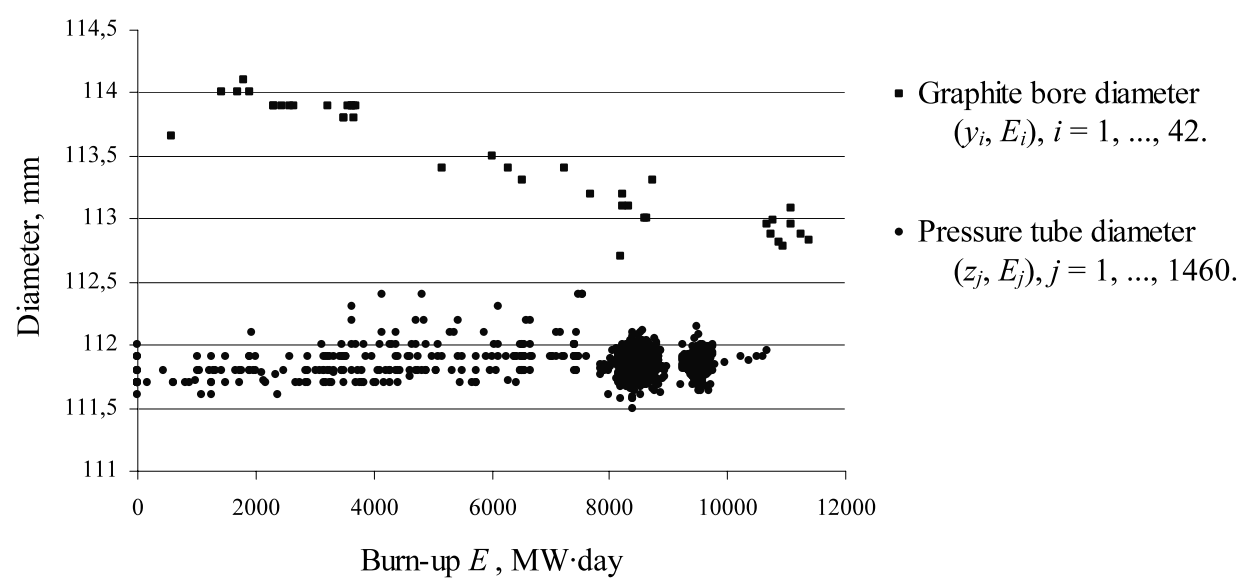

Fig. 3. Minimal graphite bore diameters and maximal pres-sure tube diameters in Unit 2.

and specially integrated software into ABAQUS. It allows to model graphite mechanic properties dependence on burn-up. Note that ABAQUS calculations were performed using measurements in Unit 1.

According ABAQUS estimations graphite bores $(G B)$ diameter dependence on the burn-up is approximated by polynomial function (Fig. 4).

$$
y(E)=k_{0}+k_{1}^{\prime} E+k_{2}^{\prime} E^{2}+k_{3}^{\prime} E^{3}+k_{4}^{\prime} E^{4}+k_{5}^{\prime} E^{5},
$$

here $E=$ (energy) burn-up. Pressure tube measurements were approximated by linear trend (Fig. 4)

$$
z(E)=b \cdot E+a
$$




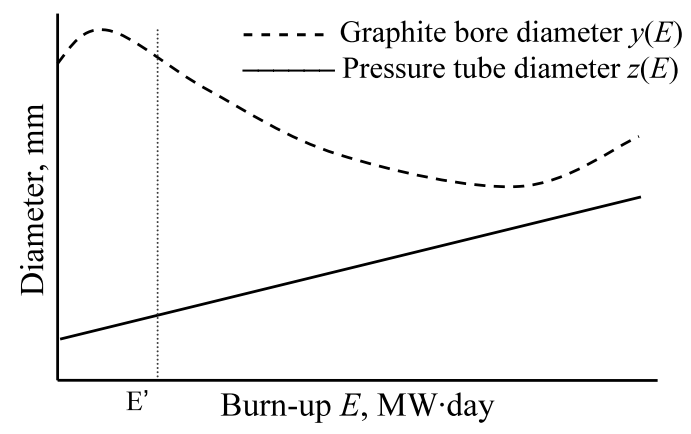

Fig. 4. Graphite bore diameters' and pressure tube diameters' dependence on the burn-up trend functions.

Considering errors of measurements parameters $k_{i}^{\prime}, i=1, \ldots, 5$, and $b$ may be assumed as random variables (note, $k_{0}$ and $a$ are obtained from technical specification of new graphite bore and pressure tube).

Period, when burn-up $E<E^{\prime}$, isn't very important for the gap closure analysis, therefore $G B$ diameter dependence on the burn-up in the remaining period can be modeled by more simple polynomial (it is more convenient for calculations)

$$
y(E)=k_{0}+k_{1} E+k_{2} E^{2}+k_{3} E^{3},
$$

here $E=$ (energy) burn-up.

Algorithm based on BA for this task is more advantageous because of some reasons:

- quite lot of direct measurements of pressure tube and graphite bores of Unit 1 were performed that were used for ABAQUS model; applying just ABAQUS model for measurements in Unit 2 can lead estimates of high uncertainty because of lack of observations;

- prior information about phenomena of graphite changes (Fig. 4) under the influence of bur-up $E$ is very important (under the influence of temperature and neutron flux, the pressure tubes expand and the graphite blocks swell up to a certain time after which they begin to compress). In this case usable algorithm has to take account of this phenomena; for instance, dependence function (estimates of its parameters) obtained by least squares method doesn't suit graphite physical property.

\subsection{Modified Application of Bayesian Approach for Updating Estimates of Parameters}

A prior information for calculations. Assume that the distribution of statistical data $y_{i}, i=1, \ldots, m$, measures of graphite bore inner diameter, is normal (conservatively) with mean $G B(E)$ defined by Eq. (3.3) and standard deviation - 0.29 (Augutis et al., 2006). For the measurement technological channels are selected with maximum burn-up. It is quite probable that graphite bore has minimum diameter in these channels; therefore extreme value distribution could be used to approximate graphite bore measurements. In this paper there is considered case when normal distribution is used, because it leads 
more conservative estimates (according to performed $\chi^{2}$ goodness-of-fit test normal distribution is appropriate). Random parameters' $k_{j}, j=1, \ldots, 3$, a prior distributions are normal as well (because of normal distribution of the observations), with means equal to ABAQUS' estimates $a_{1}=-8.93 \cdot 10^{-5}, a_{2}=-7.84 \cdot 10^{-9}, a_{3}=6.16 \cdot 10^{-13}$ and standard deviations -0.2 conservatively (Augutis et al., 2006). Obtained ABAQUS' estimates for Unit 1 could be used as initial point for Unit 2 because the same type of graphite was used in Unit 1 . Note that the parameter $k_{0}=114.1$ for Ignalina NPP Unit 1.

Modified BA was applied incorporating measurements of graphite bore inner diameter of Unit 2 into prior model (when burn-up $E>2000$, i.e., \# measurements $=20$; measurements of inner graphite bore diameter $-y_{i}, i=22, \ldots, 42$, its corresponding energy burn-up $\left.E_{i}, i=22, \ldots, 42\right)$. The estimates of random parameters are obtained from posterior pdf

$$
\begin{aligned}
\varphi\left(x_{1}, x_{2}, x_{3} \mid y_{22}, \ldots, y_{42}\right) \\
=\prod_{j=1}^{3} \exp \left[-\frac{\left(x_{j}-a_{j}\right)^{2}}{2 \cdot(0.2)^{2}}\right] \\
\quad \times \prod_{i=22}^{42} \exp \left[-\frac{\left(y_{i}-\left(k_{0}+x_{1} E_{i}+x_{2} E_{i}^{2}+x_{3} E_{i}^{2}\right)\right)^{2}}{2 \cdot(0.29)^{2}}\right] \\
\quad \times\left\{\int_{-\infty}^{\infty} \int_{-\infty}^{\infty} \int_{-\infty}^{\infty} \prod_{j=1}^{3} \exp \left[-\frac{\left(u_{j}-a_{j}\right)^{2}}{2 \cdot(0.2)^{2}}\right]\right. \\
\left.\quad \times \prod_{i=22}^{42} \exp \left[-\frac{\left(y_{i}-\left(k_{0}+u_{1} E_{i}+u_{2} E_{i}^{2}+u_{3} E_{i}^{2}\right)\right)^{2}}{2 \cdot(0.29)^{2}}\right] \mathrm{d} u_{1} \mathrm{~d} u_{2} \mathrm{~d} u_{3}\right\}^{-1},
\end{aligned}
$$

as expected values

$$
\begin{aligned}
& k_{j}=\int_{-\infty}^{\infty} \int_{-\infty}^{\infty} \int_{-\infty}^{\infty} x_{j} \cdot \varphi\left(x_{1}, x_{2}, x_{3} \mid y_{22}, \ldots, y_{42}\right) \mathrm{d} x_{1} \mathrm{~d} x_{2} \mathrm{~d} x_{3}, \\
& j=1, \ldots, 3
\end{aligned}
$$

Numerical values of updated parameters' estimates and updated graphite bore diameter dependence on burn-up function are presented in Table 1 and Fig. 5.

For evaluation errors there were calculated sums of squares of differences between measurements and ABAQUS graph and updated one by Bayesian approach dependence functions (Table 1). Bayesian approach gives result that has twice minimal sum of errors' squares.

\subsection{Mathematical Model for Residual Gas-Gap Assessment}

Probabilistic evaluation of the gas-gap existence is based on combination of developed models for pressure tube $(P T)$ and graphite bore $(G B)$ diameters changes. $G B$ diameter 
Table 1

Calculation results

\begin{tabular}{lcc}
\hline Estimates of coefficients & ABAQUS & Bayes \\
\hline$k_{1}$ & $-8.93 \cdot 10^{-5}$ & $-1.20 \cdot 10^{-4}$ \\
$k_{2}$ & $-7.84 \cdot 10^{-9}$ & $-6.51 \cdot 10^{-9}$ \\
$k_{3}$ & $6.16 \cdot 10^{-13}$ & $6.00 \cdot 10^{-13}$ \\
Sum of errors' squares & 1.109 & 0.3823 \\
\hline
\end{tabular}

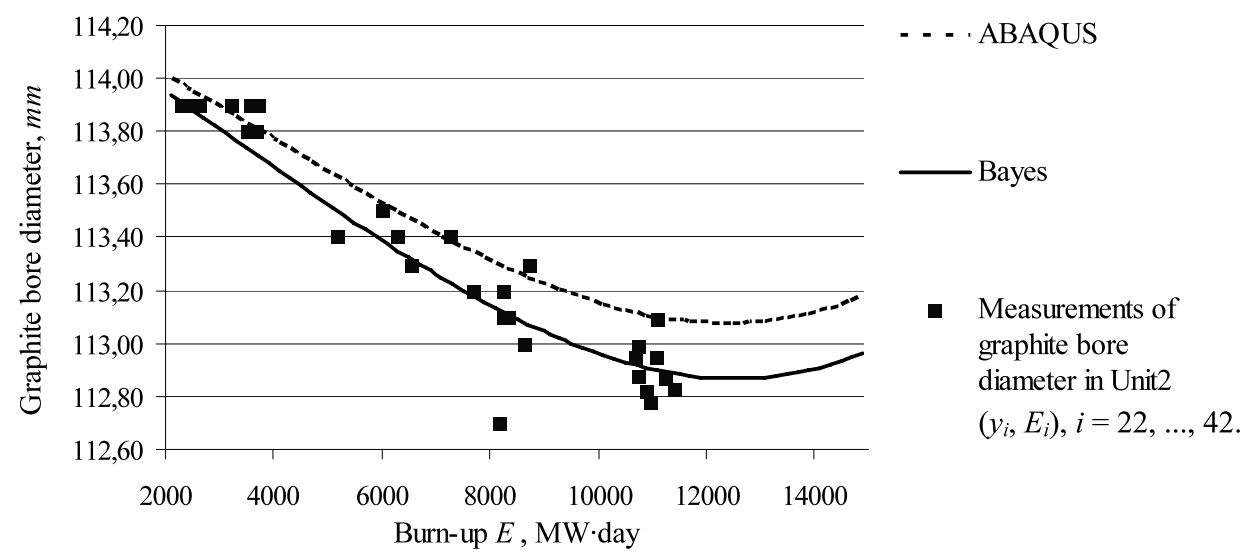

Fig. 5. ABAQUS and updated $G B$ diameter dependence on burn-up functions; measures of minimal $G B$ diameter (Unit2).

dependence on burn-up model is defined by Eq. (3.3) and pfd of its random parameters is updated by BA and defined by Eq. (3.4) with point estimates that are presented in Table 1. $P T$ diameter as random function $z(E)$ (Eq. (3.2)) follows Normal distribution with mean

$$
z(E)=0.000057 \cdot E+111.61955
$$

and standard deviation $0.16 \mathrm{~mm}$ (Augutis et al., 2004). Since there was available quite big amount of repetitive measurements of $P T$ diameters, it was possible to check the accuracy of the linear model, which appeared to be very high.

Mathematically the gas-gap is determined as difference between $P T$ and GR

$$
\delta(E)=y(E)-z(E)=b_{0}+b_{1} E+b_{2} E^{2}+b_{3} E^{3}
$$

i.e., its density function is obtained as convolution - distribution of sum of independent random functions (random parameters of Eqs. (3.2) and (3.3) follow Normal distribution, $G G(E)$ follows normal distribution as well). Parameters of gas-gap model, defined by equality (3.7), are

$$
b_{0}=k_{0}-a
$$




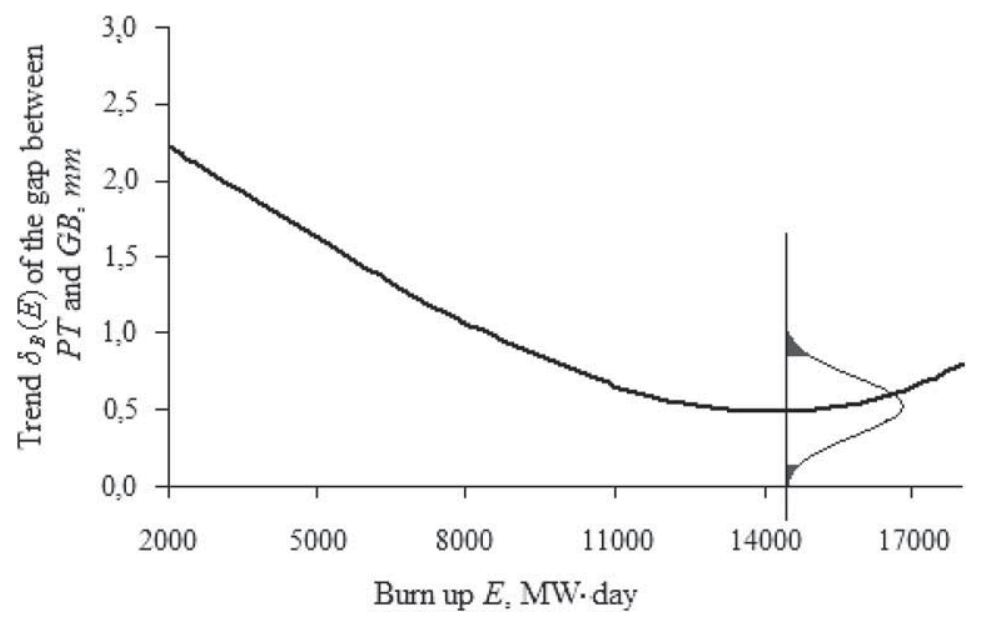

Fig. 6. The trend of the gap between $G B$ and $P T$.

$$
\begin{aligned}
& b_{1}=k_{1}-b, \\
& b_{2}=k_{2}, \\
& b_{3}=k_{3} .
\end{aligned}
$$

To obtain trend function $\delta_{B}(E)$ (expected value) of the gap between $G B$ and $P T$ random parameters are replaced with its estimates (Table 1 and Eq. (3.6)). This trend function $\delta_{B}(E)$ is presented in Fig. 6 .

According to performed probability safety analysis of Ignalina NPP (with respect of remaining gas-gap) forecasted burn-up $E^{*}=14660 \mathrm{MW} \cdot$ day in the end of 2009 (before the shutdown of unit 2). For this burn up $E^{*}$ : expected value of gas-gap $\delta_{B}\left(E^{*}\right)=0.49 \mathrm{~mm}$; its asymmetric $95 \%$ confidence interval $[0.12 ; 0.91]$ (with probabilities of 0.03 and 0.02 in tails).

The gas-gap behavior describing function (3.7) could be updated by Bayesian approach with new available measurements of gap between $P T$ and $G B$ by ultrasonic technology. The analysis of gas-gap closure is important for both exploitation of Unit 2 and dismantlement of Unit 2.

\section{Results and Conclusions}

The algorithm for estimation (and updating estimates) of random characteristics that describes systems', equipments' or substance' dynamics when those characteristics as functions of some factors behaviors are priory known was developed and presented in the paper.

Parameters' estimates of graphite bore (of Ignalina NPP RBMK-1500 reactor) diameters dependence on burn-up function (polynomial) was updated using developed algorithm incorporating GB measurements of Unit 2. In considered case estimates obtained 
by BA are approximately $65 \%$ more precise then ABAQUS estimates. Obtained parameters' density functions were used to construct the mathematical model of gas-gap that could be updated when new gas-gap measurements in Unit 2 would be made using ultrasonic technology. The asymmetric $95 \%$ confidence interval (with probabilities of 0.03 and 0.02 in tails) of remaining gas-gap was calculated; it satisfies safety requirements.

\section{References}

Augutis, J., Ušpuras, E. (2006). Risk of Technologies. Kaunas (in Lithuanian).

Augutis, J., Simaitytė, J., Ušpuras, E., Alzbutas, R., Matuzas, V. (2004). Estimation of the gas gap between the channels and the graphite masonry in an RBMK-1500 reactor. Atomic Energy, 96(4), 241-245.

Bernardo, J.M., Smith, A.F.M. (2003). Bayesian Theory. Wiley.

Caplinskas, A. (2009). Requirements elicitation in the context of enterprise engineering: A vision driven approach. Informatica, 20(3), 343-368.

Dzemyda, G., Sakalauskas, L. (2009). Optimization and knowledge-based technologies. Informatica, 20(2), $165-172$.

Littlewood, B., Popov, P., Strigini, L. (2000). Assessment of the reliability of fault-tolerant software: A Bayesian approach. In: Proc. 19th International Conference on Computer Safety, Reliability and Security, SAFECOMP'2000, Rotterdam, the Netherlands, Springer.

RSR (1997). Review of the Ignalina Nuclear Power Plant Safety Analysis Report.

SAR (1996). Ignalina Safety Analysis Report. Final edition issued by Vattenfall Nuclear Project AB for the Ignalina Nuclear Power Plant.

I. Žutautaitė-Šeputienė is a PhD student at Vytautas Magnus University and also an engineer at Lithuanian Energy Institute (Laboratory of Nuclear Installations Safety). Her research interest includes probability safety analysis.

J. Augutis is a professor, doctor (habilitatis) in mathematics and energetics, vice rector for research of Vytautas Magnus University, expert of Lithuanian Academy of Science. His scientific interests are risk analysis, mathematical models of systems reliability and nuclear installations safety analysis, energy security of supply analysis. He is a member of editorial boards of journals "Energy", "Journal of Civil Engineering and Management", "Journal of Mathematics and Mathematical Modeling".

L. Telksnys professor, doctor habilitatis in informatics, Doctor Honoris Causa of the Kaunas University of Technology, member of Lithuanian Academy of Sciences, head of Recognition Processes Department at the Institute of Mathematics and Informatics, Vilnius, Lithuania. He is the author of an original theory of detecting changes in random processes, investigator and developer of a computerized system for statistical analysis and recognition of random signals. His current research interests are in analysis and recognition of random processes, cardiovascular signals and speech processing and computer networking. 


\section{RBMK tipo branduolinio reaktoriaus duju tarpelio matematinio modelio parametru vertinimas Bajeso metodu}

Inga ŽUTAUTAITĖ-ŠEPUTIENĖ, Juozas AUGUTIS, Laimutis TELKSNYS

Straipsnyje pristatytas algoritmas, leidžiantis apskaičiuoti nestacionariu procesų (pavyzdžiui, ịrenginiu senejjimo proceso) matematiniu modeliu parametru ịverčius bei juos patikslinti, panaudojant apriorinę informaciją ir gautus stebejjimo arba matavimų duomenis. Pasiūlytas algoritmas yra paremtas modifikuotu Bajeso metodo taikymu. Sudarytas algoritmas buvo panaudotas atliekant Ignalinos atominès elektrinès antro energetinio bloko RBMK-1500 tipo reaktoriaus duju tarpelio (tarp technologinio kuro kanalo ir jị supančiu grafito žiedu) užsidarymo tikimybinę analizę. 